\title{
Solubility of Silver and Palladium in $\mathrm{BaTiO}_{3}$
}

\author{
Shao-Ju Shih and Wei-Hsing Tuan* \\ Department of Materials Science and Engineering, National Taiwan University, Taipei, Taiwan 106, Republic of China
}

\begin{abstract}
Silver, palladium, and their alloys are frequently used as electrode materials for $\mathrm{BaTiO}_{3}$ (BT) based dielectrics. However, the electrodes and dielectrics usually are cofired at high temperatures, and silver and palladium can dissolve into the BT during cofiring. In the present study, the solubility of silver and palladium into BT after cofiring was determined. Three measurement techniques were used to determine solubility: chemical analysis, structural analysis, and dielectric analysis. The solubility of the silver in the BT was low, $450 \mathrm{ppm}$, after cofiring at $1290^{\circ} \mathrm{C}$ for $2 \mathrm{~h}$ in air. The diffusion distance of the silver ions into the BT was $>5 \mu \mathrm{m}$. The solubility of the palladium in the BT was even lower, $50 \mathrm{ppm}$ at $1290^{\circ} \mathrm{C}$, and the diffusion distance was $\sim 1 \mu \mathrm{m}$. The solubility of both the silver and the palladium in the BT decreased as the oxygen partial pressure of the sintering atmosphere decreased. These results demonstrated that both silver and palladium solutes act as acceptors for BT.
\end{abstract}

\section{Introduction}

$\mathrm{D}$ IELECTRIC ceramics, such as $\mathrm{BaTiO}_{3}$ (BT), $\mathrm{PbTiO}_{3}$ (PT), $\mathrm{PbZrO}_{3}(\mathrm{PZ}), \mathrm{PbZrTiO}_{3}(\mathrm{PZT}), \mathrm{PbMgNbO}_{3}(\mathrm{PMN}), \mathrm{PbNb}-$ $\mathrm{NiO}_{3}(\mathrm{PNN})$, and $\mathrm{PbLaZrTiO}_{3}$ (PLZT), all have very high permittivity. These dielectrics are widely used as materials for many electronic components. With the surge in needs for nonvolatile memory, research on these materials has accelerated recently.

For electronic components, input and output signals are transmitted in and out of ceramics through metallic electrodes. To increase volume efficiency, electrodes are applied both outside and inside the ceramics. The volume efficiency is increased further by decreasing the dielectric thickness, as shown in Fig. 1, using a multilayer ceramic capacitor (MLCC) as an example. For a dielectric thickness of $20 \mu \mathrm{m}$ and an inner electrode thickness of $2 \mu \mathrm{m}$, the effective volume fraction of metal in an MLCC structure is $10 \%$. When the dielectric thickness is decreased to $5 \mu \mathrm{m}$, soon to become common practice, the volume fraction of metal in the MLCC structure jumps to $40 \%$. The performance of the electronic component no longer depends solely on the ceramic itself but, rather, on the ceramic/metal combination.

The most readily available material for electrodes is silver (Ag). ${ }^{1}$ Silver is one of the few metals that can be fired in air at high temperature without oxidation problems. Therefore, silver can cofire with dielectrics in air. However, silver can diffuse (in the form of ions) $)^{2-15}$ and transport (in the form of vapor) ${ }^{16}$ into the dielectrics at high temperature. Silver can also migrate at low temperature. ${ }^{17}$ To solve such problems, $10 \%-30 \%$ palladium $(\mathrm{Pd})$ frequently is added to the silver, to enhance its stability at both high and low temperatures. ${ }^{16,18}$

D. Johnson-contributing editor

Manuscript No. 10070. Received May 23, 2003; approved November 24, 2003 Supported by the National Science Council, Republic of China, through Contract No. NSC89-2216-E002-049.

*Member, American Ceramic Society.
The effect of silver doping on dielectrics such as $\mathrm{BT},{ }^{2-6}$ PMN,${ }^{7,10,11}$ PZT,,${ }^{9,12}$ PLZT, ${ }^{8}$ PMN-PZT, ${ }^{9}$ PMN-PT, ${ }^{13,14}$ PMNPZN-PT, ${ }^{15}$ PNN-PT, ${ }^{14}$ and PNN-PT-PZ ${ }^{14}$ has attracted much attention recently. These studies all claim that silver can diffuse into dielectrics at high temperature. The presence of silver solutes and silver inclusions can degrade electrical performance; however, silver solutes and silver inclusions often also induce the opposite effect. ${ }^{3,13}$ Therefore, it is important to determine the solubility of silver in ferroelectrics. Unfortunately, previous studies have paid little attention to this important issue, although they all have acknowledged that the solubility of silver in most dielectrics is low. Perhaps as a result of this low solubility, the sparsely reported values also are inconsistent. For example, despite the strong influence of oxygen partial pressure on solubility, ${ }^{19}$ the reported value for the solubility of silver in BT sintered in nitrogen is 300 $\mathrm{ppm},{ }^{2}$ and the value for silver solubility in BT sintered in air is also $\sim 300$ ppm. $^{3}$

The effect of palladium on dielectrics has attracted much less attention than that of silver. The effects of palladium on dielectric performance have been reported only for the systems BT, ${ }^{5} \mathrm{PZT},{ }^{9}$ PMN-PZT, ${ }^{9}$ and PMN-PT. ${ }^{13}$ Sato et al. ${ }^{13}$ reported that almost no palladium can dissolve into PMN-PT. In any case, no specific value for the solubility of palladium in dielectrics has been reported up to now.

Determining the solubility of a minor element is a challenging task. For the case of silver solubility in dielectrics, many techniques have been used. These methods can be grouped into direct and indirect methods. Direct methods are energy-dispersive X-ray spectroscopy (EDX), ${ }^{7}$ Auger electron spectroscopy (AES), ${ }^{12}$ electron-probe microanalysis (EPMA), ${ }^{3,9}$ and techniques involving the diffusion of silver radioactive tracers. ${ }^{14}$ Indirect methods measure either the Curie temperature, $T_{\mathrm{c}}$, by determining the permittivity-temperature curves, ${ }^{2,13}$ or the lattice constant, by $\mathrm{X}$-ray diffractometry (XRD). ${ }^{3,9,13}$ Each analysis technique has its own merits and limitations. Nevertheless, no single measurement technique can produce a reliable result unless it is cross-checked by other techniques, especially when solubility is extremely low.

In the present study, the solubility of silver and palladium in BT was determined using three techniques: a chemical method, a structural analysis method, and a dielectric analysis method. The role of silver and palladium as acceptors or donors to BT also was investigated.

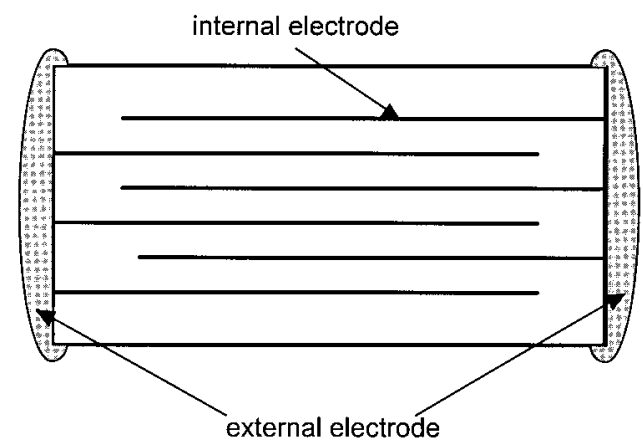

Fig. 1. Schematic of a multilayer structure. 


\section{Experimental Procedure}

$\mathrm{BaTiO}_{3}$ powder (Product No. 219-6, Lot No. 2189-6, Ferro Co., Niagara Falls, NY) was mixed with 100, 300, 1000, and 10000 ppm silver or palladium, using $\mathrm{AgNO}_{3}$ (Johnson Matthey, Inc., Haverhll, MA) and $\mathrm{Pd}\left(\mathrm{NO}_{3}\right)_{2}$ (Degussa AS, Frankfurt, Germany) as the starting sources. The mean particle size of the BT powder was $1.2 \mu \mathrm{m}$, the $\mathrm{Ba} / \mathrm{Ti}$ value was 0.995 , and the impurity levels were 910 ppm $\mathrm{SrO}, 600$ ppm $\mathrm{P}_{2} \mathrm{O}_{5}, 560$ ppm SO $\mathrm{S}_{3}, 500 \mathrm{ppm} \mathrm{CaO}$, $180 \mathrm{ppm} \mathrm{SiO}_{2}, 170 \mathrm{ppm} \mathrm{Na}_{2} \mathrm{O}, 160 \mathrm{ppm} \mathrm{ZrO}_{2}$, and $150 \mathrm{ppm}$ $\mathrm{Al}_{2} \mathrm{O}_{3}$, as reported by the manufacturer. The powder mixtures were ball-milled in ethyl alcohol, using zirconia media, for $24 \mathrm{~h}$. The slurry was then left unstirred for another $24 \mathrm{~h}$, after which it was dried with a rotary evaporator and sieved through a No. 150 plastic mesh. Calcination was conducted at $300^{\circ} \mathrm{C}$ for $4 \mathrm{~h}$ or at $500^{\circ} \mathrm{C}$ for $24 \mathrm{~h}$ for the $\mathrm{BT} / \mathrm{AgNO}_{3}$ and $\mathrm{BT} / \mathrm{Pd}\left(\mathrm{NO}_{3}\right)_{2}$ powder mixtures, respectively. Calcination profiles were chosen to ensure full decomposition of the nitrates. The calcined powder mixtures were then sieved again. Powder compacts $10 \mathrm{~mm}$ in diameter and $\sim 3 \mathrm{~mm}$ thick were formed by applying uniaxial pressure at 30 $\mathrm{MPa}$. The resulting green density was $\sim 54 \%$. The sintering profile used was $1290^{\circ} \mathrm{C} / 2 \mathrm{~h}$, with a heating rate of $3^{\circ} \mathrm{C} / \mathrm{min}$ and a cooling rate of $5^{\circ} \mathrm{C} / \mathrm{min}$. The sintering atmospheres used were flowing air, nitrogen $\left(1 \mathrm{ppm} \mathrm{O}_{2}\right)$, and oxygen.

A surface layer $\sim 0.5 \mathrm{~mm}$ thick was removed from the sintered specimens, using $\mathrm{SiC}$ sandpaper, before any measurements were taken. The final density was determined using the Archimedes method. Because the solubilities of the silver and the palladium in the BT were low, as will be demonstrated later, the theoretical density of the silver-doped BT was estimated using $6.02 \mathrm{~g} / \mathrm{cm}^{3}$ for BT, $10.5 \mathrm{~g} / \mathrm{cm}^{3}$ for silver, and $12.02 \mathrm{~g} / \mathrm{cm}^{3}$ for palladium. The polished surface was prepared by grinding with $\mathrm{SiC}$ particles and polishing with $\mathrm{Al}_{2} \mathrm{O}_{3}$ particles. Grain boundaries were revealed by etching with an aqueous solution of $\mathrm{HCl}$ and $\mathrm{HF}$. The solution was dilute enough to leave the silver and palladium inclusions intact. The microstructure was observed by optical microscopy and scanning electron microscopy. Phase identification was performed using XRD at a scanning rate of $0.05^{\circ} 2 \theta / \mathrm{s}$.

Three techniques were used to determine the solubility of the silver and the palladium in the BT, as described next.

\section{(1) Chemical Analysis (Electron Probe Microanalysis)}

EPMA (Model JAX-8600SX, JEOL, Tokyo, Japan) was used under the operation conditions of $15 \mathrm{kV}$ and $1 \times 10^{-7} \mathrm{~A}$, which resulted in an electron probe with a spot size of $1.5 \mu \mathrm{m}$. Only specimens doped with $0.1 \%$ and $1 \%$ silver were used for this analysis. The specimens were polished before measurement. An undoped BT specimen was used as a reference. For the present study, the silver and palladium particles were mixed intimately with the BT particles. One silver or palladium inclusion in the BT matrix was located first, and then EPMA was used to analyze every micrometer along a straight line from the chosen silver or palladium inclusion. Approximately 20 points (a distance of 20 $\mu \mathrm{m})$ were measured. For each composition, five different locations were chosen randomly. Therefore, $\sim 100$ points were measured for each composition.

\section{(2) Structural Analysis (c/a Value)}

XRD under the operation conditions of $30 \mathrm{kV}$ and $20 \mathrm{~mA}$ was used for structural analysis. A slow scanning rate, $0.01^{\circ} 2 \theta / \mathrm{s}$ and $2 \mathrm{~s} / \mathrm{step}$, was used to determine the $d$-spacing values for the (002) and (200) planes of the BT. The values determined for the $d$-spacings were used to calculate the $c / a$ value. Three specimens were used for each composition.

\section{(3) Dielectric Measurement (Curie Temperature)}

The permittivity was measured using a LCZ meter (Model HP 4272A, Hewlett-Packard Co., Palo Alto, CA) with $1 \mathrm{~V}$ signal at 1 kHz. Silver paste (N2796, Shoei Co., Niagara Falls, NY) was applied as an electrode. The permittivity-temperature curves were determined by maintaining the specimens at each temperature for
9 min and then measuring the capacitance. The Curie temperature, $T_{\mathrm{c}}$, was determined from the resulting curves. Two specimens were used for each composition.

\section{Results}

For the specimens sintered in air, nitrogen, and oxygen, XRD analyses showed only BT and silver or palladium in the $1 \%$-Agdoped or $1 \%$-Pd-doped BT, respectively. However, no silver or palladium was found in the 100, 300, and $1000 \mathrm{ppm}$ Ag-doped and Pd-doped BT, because of their low dopant content. Figure 2 shows the typical microstructures of the Ag-doped and Pd-doped BT. The BT grains exhibited a bimodal size distribution. The silver and palladium inclusions distributed either within BT grains or at their grain boundaries. The relative densities of all specimens prepared in the present study varied within a rather narrow range, from $96.3 \%$ to $98.6 \%$. The size of the silver inclusions varied from 1.1 to $2.2 \mu \mathrm{m}$ and that of the palladium inclusions from 0.6 to $1.1 \mu \mathrm{m}$.

Silver can vaporize during cofiring with $\mathrm{BT},{ }^{3,13}$ and a silverdepleted surface layer indeed was observed. However, the amount of silver added was small, and the silver content remaining in the specimen after surface removal was close to the added amount. For the Pd-doped specimens, vaporization was not a problem. ${ }^{1}$

\section{(1) Electron Probe Microanalysis}

The amount of silver and palladium added to the BT matrix was small. When the solubility of the silver and palladium was zero, the volume fraction of silver and palladium was as low as $0.58 \%$ and $0.50 \%$, respectively, for the $1-\mathrm{wt} \%$-Ag-doped and $1-\mathrm{wt} \%$-Pddoped specimens. However, when the solubility of the silver and palladium in the BT was not zero, their volume fraction was even smaller. For a composite containing monosized inclusions, the nearest-neighbor distance, $\lambda$, between inclusions depended on the size of the inclusions, $d$, and their volume fraction, $F$, as follows: 20,21

$$
\lambda=\left(\frac{\pi}{6}\right)^{1 / 2}\left(\frac{d}{F^{1 / 2}}\right)
$$

This result suggests that the distance between two nearby metallic inclusions was $>20$ and $>10 \mu \mathrm{m}$ for Ag-doped and Pd-doped BT, respectively. The ability of the electron probe to spot several metallic inclusions within a short distance, e.g., $20 \mu \mathrm{m}$, was low. Therefore, we had to locate one metallic particle first to start each EPMA analysis.

Figure 3 shows typical EPMA results for the 0.1\%-Ag-doped and $1 \%$-Ag-doped specimens. These specimens were sintered in air. For the $0.1 \%$-Ag-doped BT, only one silver inclusion was spotted within a distance of $20 \mu \mathrm{m}$ (Fig. 3(a)). The Ag signal at the $\mathrm{Ag}$ inclusion is very high, and then drops to a saturated value. It suggests that the silver solubility was $550 \mathrm{ppm}$ in this specific case. The length of the saturated plateau is longer than $5 \mu \mathrm{m}$, indicating that the diffusion distance of the silver ions in the BT matrix was $>5 \mu \mathrm{m}$. A typical result for the $1 \%$-Ag-doped BT specimen showed a similar value (Fig. 3(b)), except that the detection line crossed two silver inclusions. Five different locations were randomly chosen for each composition. The average values and their standard deviations are shown in Table I.

Figure 4 shows typical EPMA results for the Pd-doped BT specimen. A small plateau occurs from 4 to $5 \mu \mathrm{m}$, followed by a sudden drop to $0 \mathrm{ppm}$. This result indicates that the diffusion distance of the palladium into the BT was extremely small. Five different locations were chosen randomly, and a short plateau occurred in most cases. The plateau was considered an indication of the solubility of the palladium in the BT. The average values and their standard deviations for palladium doping are shown in Table II.

Figure 5 shows the EMPA results for the Ag-doped and Pd-doped BT sintered in nitrogen. The solubility of the silver in the BT, taken from the short plateau shown in Fig. 5(a), was 110 ppm in this specific case. The average of the five measurements is 

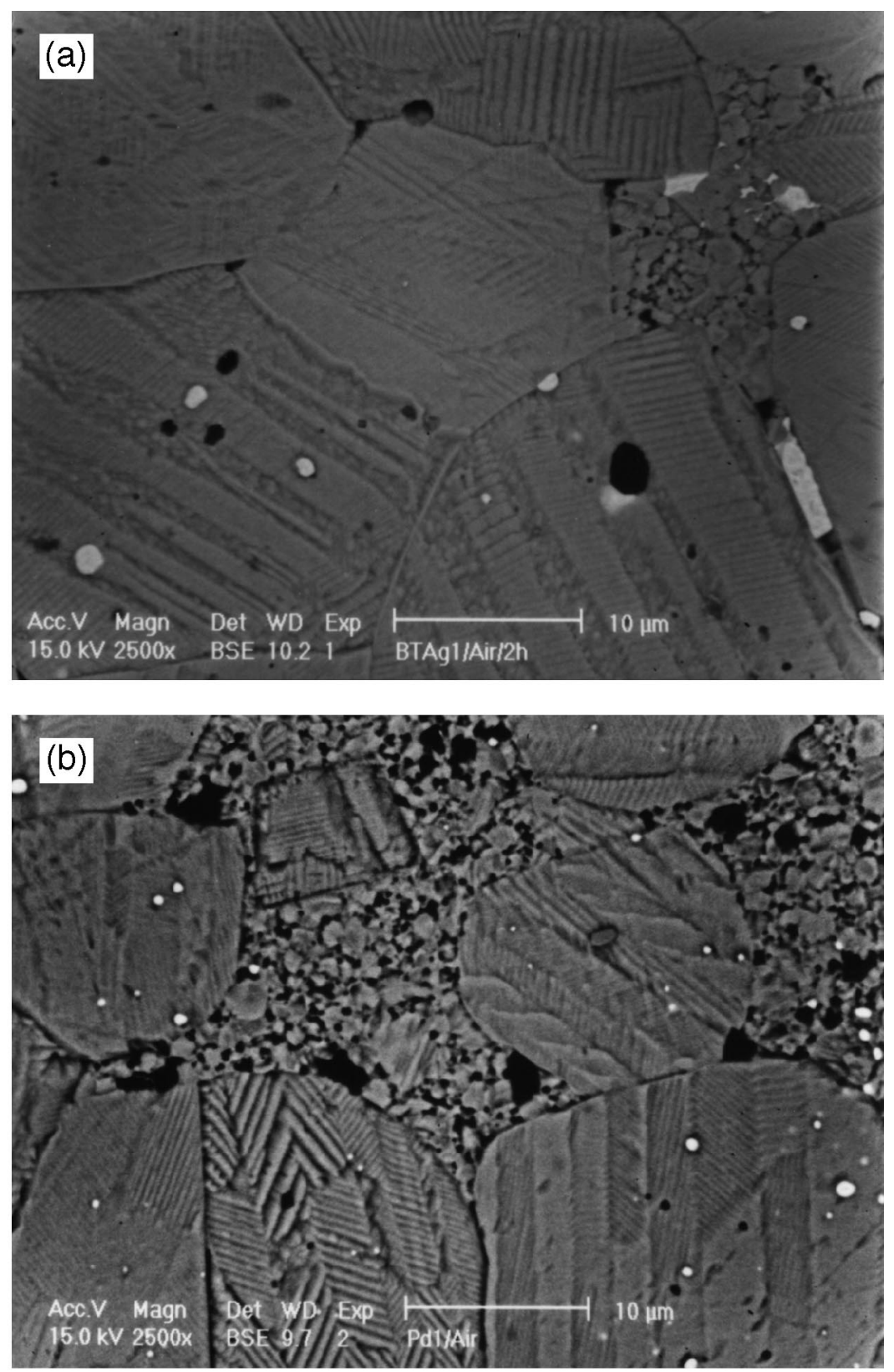

Fig. 2. Typical SEM micrographs of the (a) $1 \%$-Ag-doped and (b) $1 \%$-Pd-doped $\mathrm{BaTiO}_{3}$. The specimens were sintered at $1290 \mathrm{C}$ for $2 \mathrm{~h}$ in air.

shown in Table I. Figure 5 also suggests that the diffusion distance of the silver ions into the BT was $\sim 1-3 \mu \mathrm{m}$. For the BT/Pd specimen, almost no plateau occurred in the palladium content versus distance curves (an example is shown in Fig. 5(b)).

Figure 6 shows the EPMA results for the Ag-doped and Pd-doped BT sintered in oxygen. The solubility of the silver in the BT was $950 \mathrm{ppm}$, with a diffusion distance $>5 \mu \mathrm{m}$ (Fig. 6(a)). The solubility of the palladium in the BT was $\sim 200 \mathrm{ppm}$, with a short diffusion distance of $1 \mu \mathrm{m}$ (Fig. 6(b)).

\section{(2) c/a Value}

The $c / a$ value for a BT crystal can be determined using a slow scanning rate for XRD analysis. The resulting values for the $c / a$ values of the Ag-doped and Pd-doped BT specimens sintered in air, nitrogen, and oxygen are shown in Fig. 7 as a function of metal content. The turning point in the figure is considered an indication of solubility. However, the turning point in Fig. 7 sometimes is not as obvious as one would expect. For example, in the case of the Ag-doped BT specimens sintered in air (Fig. 7(a)), the cla values were saturated at $300 \mathrm{ppm}$, indicating that the solubility of the silver in the BT sintered in air was $\sim 100-300$ ppm. However, for the palladium solubility in the BT sintered in air, the turning point could be located at either at 100 or $300 \mathrm{ppm}$. Based on measurements from the other two techniques, we used $100 \mathrm{ppm}$ as the solubility limit of the palladium in the BT. The results are shown in Tables I and II. The solubilities of both the silver and the palladium in the BT increased as the oxygen partial pressure increased.

\section{(3) Curie Temperature}

The permittivity-temperature curves can give the value of the Curie temperature, $T_{\mathrm{c}}$, with a sensitivity of $1^{\circ} \mathrm{C}$. Figure 8 shows the values of $T_{\mathrm{c}}$ as a function of metal addition. In the specimens sintered in air, for example, the $T_{\mathrm{c}}$ of the Ag-doped specimens decreased until the silver content reached $300 \mathrm{ppm}$, indicating that the solubility of the silver in the BT was $\sim 100-300 \mathrm{ppm}$. The solubility of the palladium in the BT was $\sim 0-100 \mathrm{ppm}$. The results for the specimens sintered in different sintering atmospheres are shown in Fig. 8 and summarized in Tables I and II. 

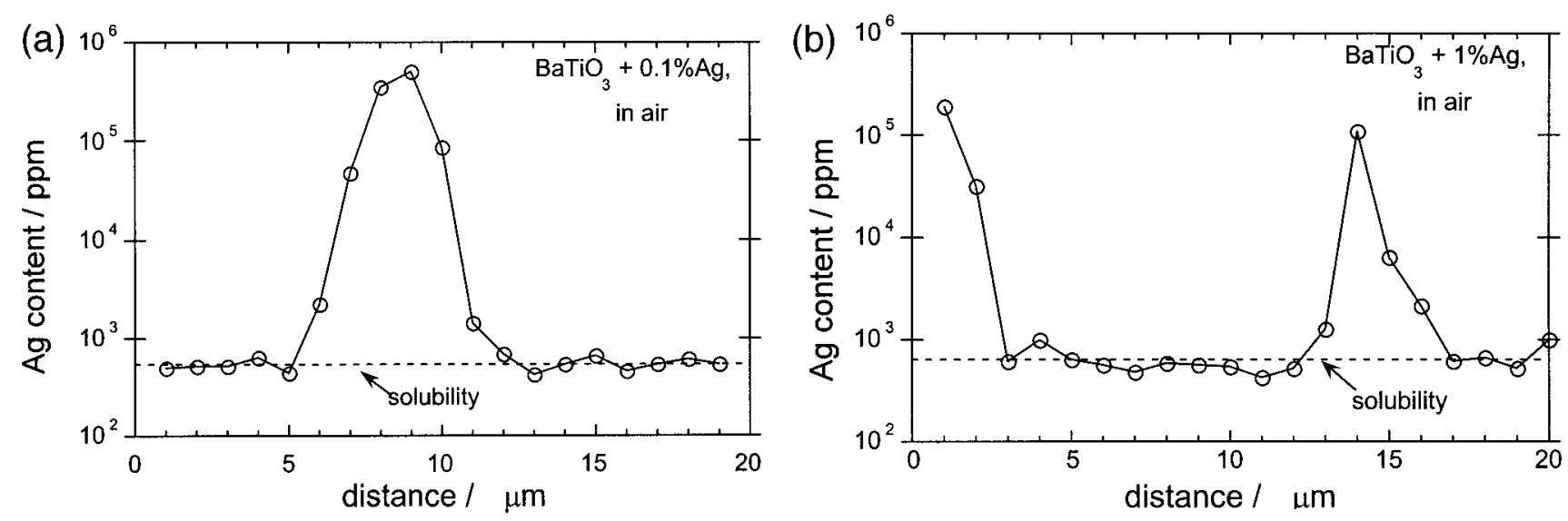

Fig. 3. Typical EPMA measurement results for the (a) $0.1-\mathrm{wt} \%$-Ag-doped and (b) 1 -wt $\%$-Ag-doped $\mathrm{BaTiO}_{3}$. The specimens were sintered at $1290 \mathrm{C}$ for $2 \mathrm{~h}$ in air.

\section{Discussion}

\section{(1) Solubility of Silver in $\mathrm{BaTiO}_{3}$}

EPMA can detect a signal both from the surface of a specimen and from below the surface (to a depth of $\sim 1.5 \mu \mathrm{m}$ ). Therefore, recording values from random spots on a specimen may overestimate solubility. A line-scanning mode usually is incorporated into most commercial EMPA equipment. However, the relatively short analysis time of that mode may lead to less accurate results. In the present study, we demonstrated that conducting EPMA point analyses along a line bypassing the inclusion can give rather reliable results. The relatively low standard deviations in Table I substantiate this finding.

EPMA also can provide a rough idea of the diffusion distance of the silver into the BT. Because EPMA always starts from a metallic particle, the signal is high at that point, then drops to a saturated plateau in which solubility can be determined. If the

Table I. Solubility of $\mathrm{Ag}$ in $\mathrm{BaTiO}_{3}$ as Determined by Using the EPMA Technique or through the Determination of the $c / a$ Ratio and $T_{\mathrm{c}}$ Values of $\mathrm{BaTiO}_{3}$

\begin{tabular}{|c|c|c|c|}
\hline \multirow[b]{3}{*}{ Technique } & \multicolumn{3}{|c|}{ Sintering atmosphere } \\
\hline & Nitrogen & Air & Oxygen \\
\hline & Ag concn (ppm) & Ag concn (ppm) & Ag concn (ppm) \\
\hline EMPA & $200 \pm 70$ & $450 \pm 70$ & $1000 \pm 40$ \\
\hline$c / a$ ratio & $0-100$ & $100-300$ & $>10000$ \\
\hline$T_{\mathrm{c}}$ & $100-300$ & $100-300$ & $>10000$ \\
\hline
\end{tabular}

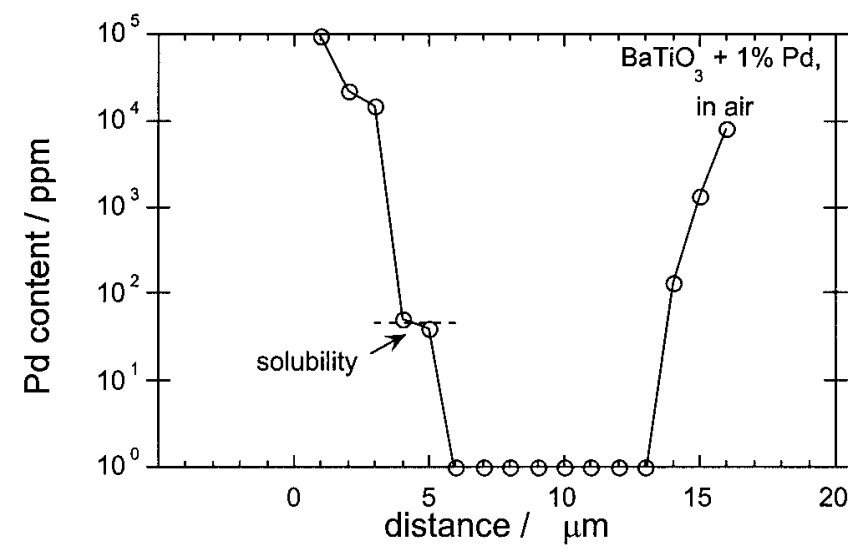

Fig. 4. Typical EPMA measurement results for the 1-wt\%-Pd-doped $\mathrm{BaTiO}_{3}$. The specimen was sintered at $1290 \mathrm{C}$ for $2 \mathrm{~h}$ in air. signal drops from the plateau to zero, then the diffusion distance can be determined. An example is shown in Fig. 5(a). However, if many silver particles are located near the surface region, or if silver ions diffuse for a long distance, it is impossible to determine a precise diffusion distance. A lower bound for the diffusion distance then is given instead. According to the present EPMA technique, the diffusion distance of the silver into the BT was $>5$ $\mu \mathrm{m}$ for the BT sintered in air and oxygen and $>1 \mu \mathrm{m}$ for the BT sintered in nitrogen.

The radius of a monovalent silver ion $(0.149 \mathrm{~nm})$ is close to that of divalent barium ion $(0.135 \mathrm{~nm}){ }^{22}$ Most previous studies have suggested that silver ions substitute for barium ions, ${ }^{2,3}$ as will be confirmed in the following section. If silver ions replace the barium ions, lattice distortion is relatively small. That fact may explain why Ikusima and Hayakawa, ${ }^{2}$ as well as Chen and Tuan, ${ }^{3}$ failed to note any change in the lattice constant of Ag-doped BT. However, the change in the $c / a$ value was significant enough to define the dissolution of the silver into the BT. That result may be attributable to the fact that both the $c$ and $a$ axes changed slightly, although in different directions. However, determining the turning point in the $c / a$ value versus silver content curve is difficult, as demonstrated in Fig. 7. The difficulty may be related to the similar ionic radii of the barium and silver ions.

The most popular analysis technique used to determine the solubility of silver in ferroelectrics involves determining the $T_{\mathrm{c}}$ value. $^{2,13}$ This technique is also frequently used to determine the solubility of other solutes in ferroelectrics. ${ }^{12,13}$ However, the change in $T_{\mathrm{c}}$ value was small in the present study. Furthermore, $T_{\mathrm{c}}$ is affected by many factors, such as the presence of internal and external stresses and microstructural features. ${ }^{12}$ Hwang et al. ${ }^{12}$ demonstrated recently that $T_{\mathrm{c}}$ is significantly biased by the presence of internal stresses in Ag-doped PZT.

Both $c / a$ and $T_{\mathrm{c}}$ values are affected by the presence of other solutes. Impurities in the powder can affect the measured results. It can be demonstrated that $c / a$ and $T_{\mathrm{c}}$ values are not the same in undoped specimens sintered in different atmospheres (Figs. 7 and 8); solubility is seriously affected by sintering atmosphere. ${ }^{19}$ Many

Table II. Solubility of $\mathrm{Pd}$ in $\mathrm{BaTiO}_{3}$ as Determined by Using the EPMA Technique or through the Determination of the $c / a$ Ratio and $T_{\mathrm{c}}$ Values of $\mathrm{BaTiO}_{3}$

\begin{tabular}{|c|c|c|c|}
\hline \multirow[b]{3}{*}{ Technique } & \multicolumn{3}{|c|}{ Sintering atmosphere } \\
\hline & Nitrogen & Air & Oxygen \\
\hline & Pd concn (ppm) & Pd concn (ppm) & Pd concn (ppm) \\
\hline EMPA & 0 & $50 \pm 20$ & $300 \pm 70$ \\
\hline$c / a$ ratio & $0-100$ & $0-100$ & $100-300$ \\
\hline$T_{\mathrm{c}}$ & 0 & $0-100$ & 0-100 \\
\hline
\end{tabular}



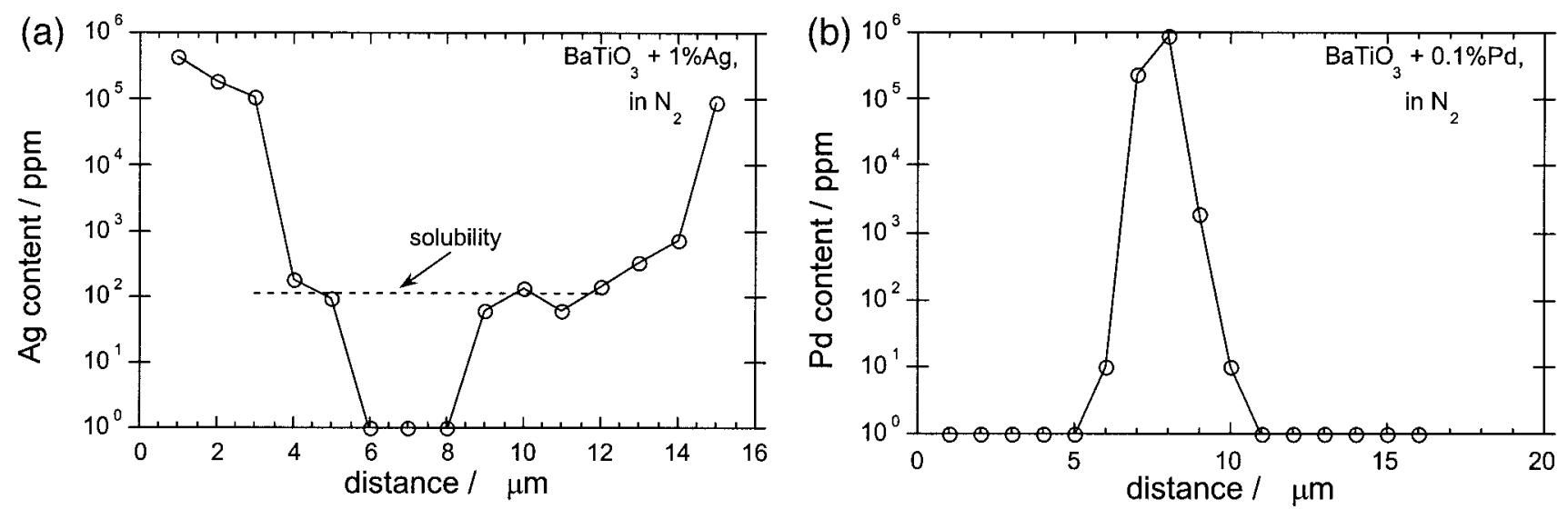

Fig. 5. Typical EPMA measurement results for the (a) 1-wt\%-Ag-doped and (b) 0.1-wt\%-Pd-doped $\mathrm{BaTiO}_{3}$. The specimens were sintered in nitrogen.

impurities exist in the starting powder, several of which, such as sodium and aluminum, are acceptors for the BT. The different solubilities of these impurities in undoped BT sintered in different atmospheres results in different $c / a$ and $T_{\mathrm{c}}$ values. To determine the effect of the silver solution, a comparison was made between undoped and doped specimens prepared by the same technique except for differences in dopant level. However, the presence of one solute may affect the solubility of another solute to a different extent at different dopant levels. ${ }^{19}$ Furthermore, determining solubility by measuring the $c / a$ and $T_{\mathrm{c}}$ values can give a range, rather then a specific value. A precise value can be determined only through exhaustive specimen preparation.

Therefore, the EMPA technique adopted in the present study seems to be the most reliable method for determining the solubility of silver in BT. The values determined by EPMA for the solubility of the silver in the BT were 200, 450, and $1000 \mathrm{ppm}$ for the BT sintered at $1290^{\circ} \mathrm{C}$ in nitrogen, air, and oxygen, respectively.

\section{(2) Solubility of Palladium in $\mathrm{BaTiO}_{3}$}

The EPMA technique used in the present study requires a solubility plateau in the EPMA intensity versus distance curve. However, the diffusion distance of the palladium into the BT was $\sim 1 \mu \mathrm{m}$ for the BT sintered in air and oxygen (Figs. 4 and 5) and $<1 \mu \mathrm{m}$ for the BT sintered in nitrogen (Fig. 6). Thus, the EPMA technique failed to deliver a persuasive result for the Pd-doped BT. However, all three techniques did result in similar values for the solubility of the palladium in the BT. The solubility of the palladium in the BT prepared by sintering in air was never zero. The most likely solubility values for the palladium into the BT are 0 , 50, and $300 \mathrm{ppm}$ for the BT sintered in nitrogen, air, and oxygen, respectively.

\section{(3) Role of Silver and Palladium Solutes}

The defect chemistry of BT has been well documented. ${ }^{19,23-25}$ If monovalent silver ions act as acceptors for Ag-doped BT, the substitution of $\mathrm{Ba}^{2+}$ can be expressed as follows:

$$
2 \mathrm{Ag}=2 \mathrm{Ag}_{\mathrm{Ba}}^{\prime}+V_{\mathrm{O}}
$$

If divalent palladium ions also act as acceptors for BT, the substitution of $\mathrm{Ti}^{4+}$ can be expressed as follows:

$$
\mathrm{Pd}=\mathrm{Pd}_{\mathrm{Ti}}^{\prime \prime}+V_{\mathrm{O}}^{*}
$$

The reduction of BT can also produce oxygen vacancies, as follows: ${ }^{19}$

$$
\mathrm{O}_{\mathrm{O}}=\frac{1}{2} \mathrm{O}_{2}+V_{\mathrm{O}}^{\ddot{*}}+2 \mathrm{e}^{\prime}
$$

Therefore, sintering BT in nitrogen can reverse reactions (2) and (3) from the right to the left, thus suppressing the solubility of the acceptors. In other words, when the solubility of an ion decreases with a decrease in oxygen partial pressure, the solute is likely to act as an acceptor. Therefore, both silver and palladium act as acceptors for BT. Because of the charge difference between $\mathrm{Ag}^{+}$ and $\mathrm{Ba}^{2+}$, the solubility of silver in $\mathrm{BT}$ is low, despite the size similarity between the two ions. The charge difference between $\mathrm{Pd}^{2+}$ and $\mathrm{Ti}^{4+}$ is relatively large; furthermore, the size difference between $\mathrm{Pd}^{2+}(0.086 \mathrm{~nm})$ and $\mathrm{Ti}^{4+}(0.061 \mathrm{~nm})^{21}$ also is large, so that the solubility of palladium in BT is extremely low.

\section{Conclusions}

Determining the solubility of silver or palladium in BT is a difficult, but nonetheless important, task. In the present study,
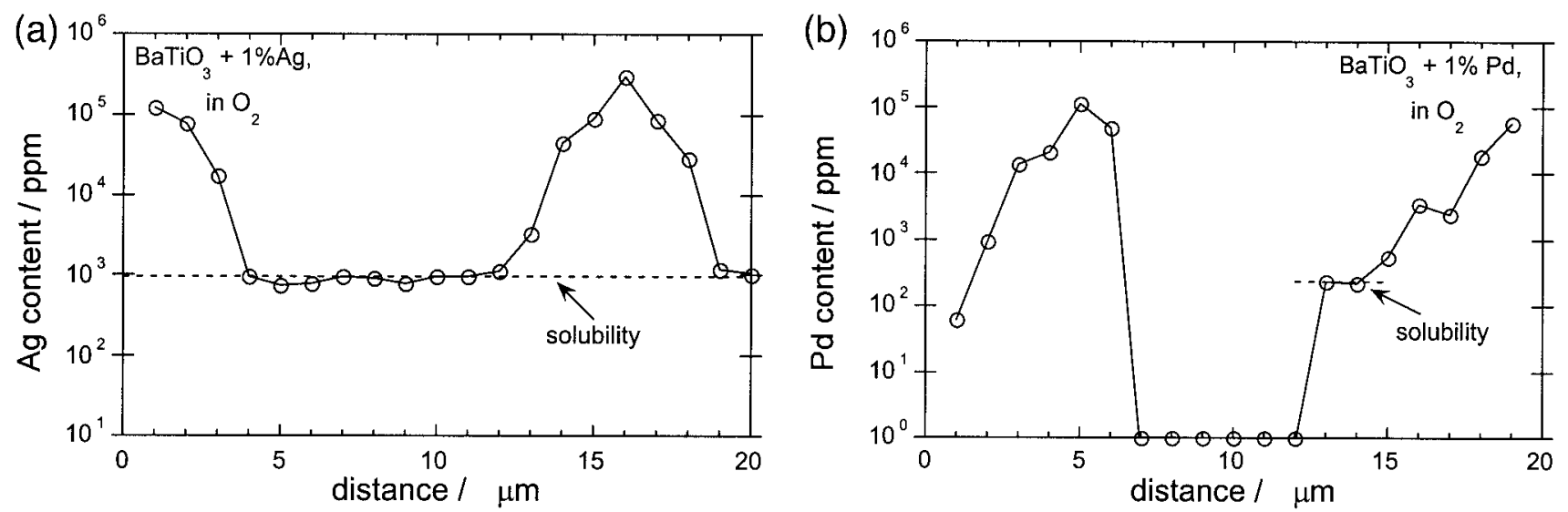

Fig. 6. Typical EPMA analysis results for the (a) 1-wt $\%$-Ag-doped and (b) 1-wt $\%$-Pd-doped $\mathrm{BaTiO}_{3}$. The specimens were sintered in oxygen. 

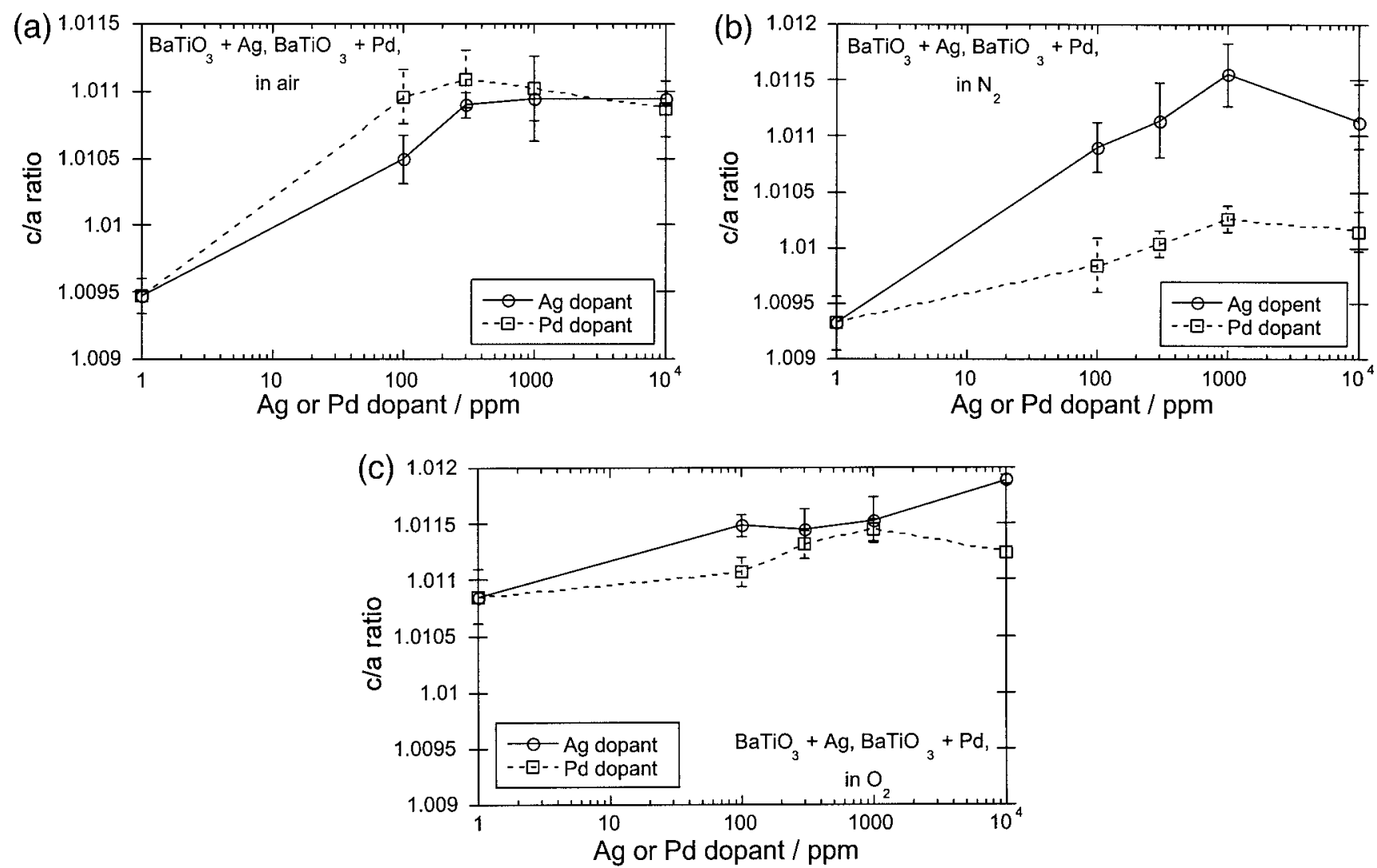

Fig. 7. Values of $c / a$ ratio as a function of $\mathrm{Ag}$ or Pd addition content. The specimens were sintered in (a) air, (b) nitrogen, and (c) oxygen.
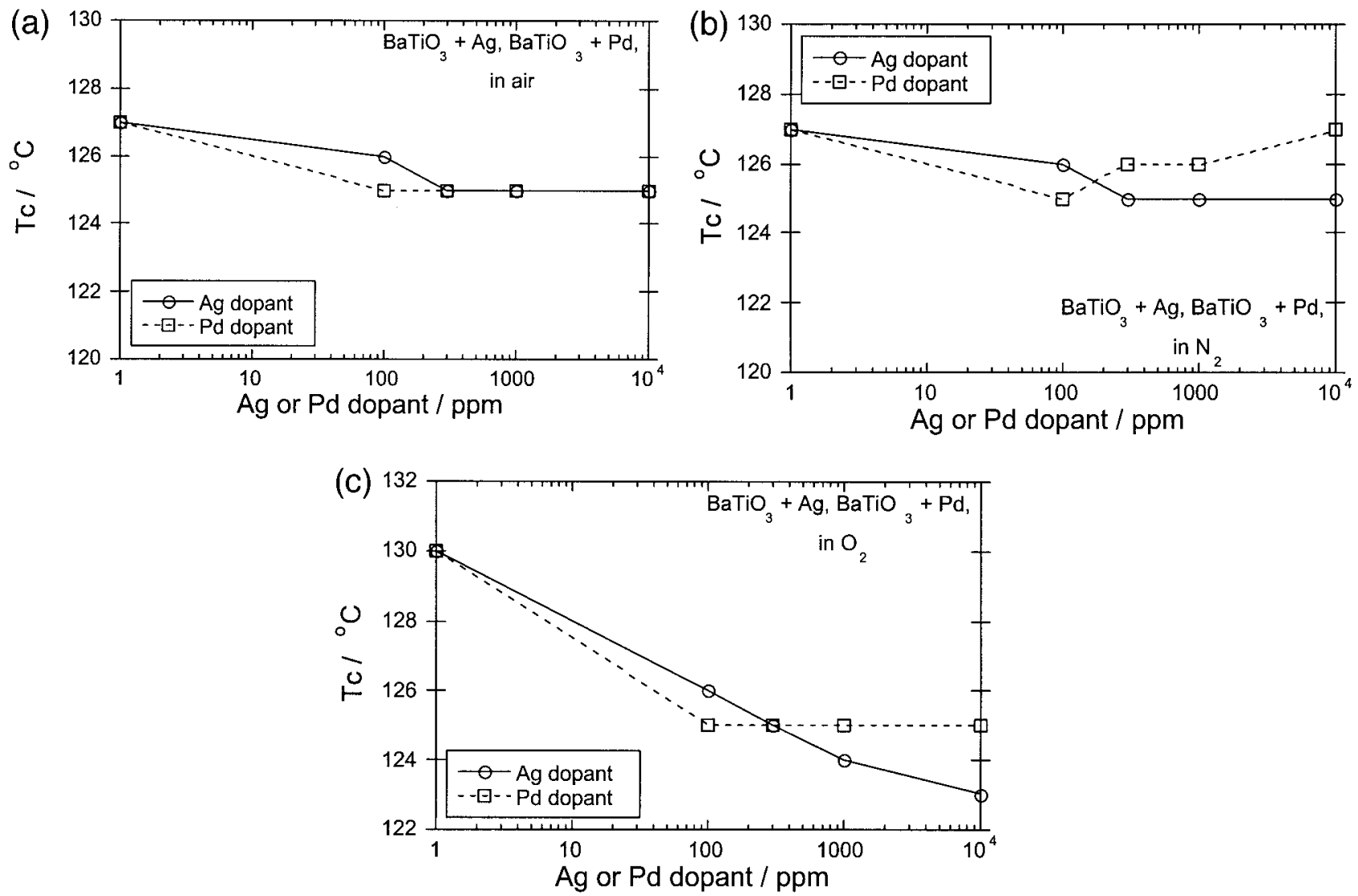

Fig. 8. Curie temperature, $T_{\mathrm{c}}$, as a function of $\mathrm{Ag}$ or Pd addition content. The specimens were sintered in (a) air, (b) nitrogen, and (c) oxygen. 
three different techniques-chemical analysis through EPMA measurement, structural analysis through determination of the $c / a$ value for BT, and dielectric analysis through the determination of $T_{\mathrm{c}}$-were used to accomplish the task. The solubility values of the silver in the BT were 200, 450, and $1000 \mathrm{ppm}$ for the BT sintered in nitrogen, air, and oxygen, respectively. The solubilities of the palladium in the BT were 0,50 , and $300 \mathrm{ppm}$ for the BT sintered in nitrogen, air, and oxygen, respectively. The diffusion distance of the silver into the BT was $>5 \mu \mathrm{m}$ for the BT sintered in air and oxygen and $>1 \mu \mathrm{m}$ for the BT sintered in nitrogen. The diffusion distance of the palladium into the BT was $<1 \mu \mathrm{m}$.

\section{References}

${ }^{1}$ S. F. Wang, J. P. Dougherty, W. Huebner, and J. G. Pepin, "Silver-Palladium Thick-Film Conductors," J. Am. Ceram. Soc., 77 [12] 3051-72 (1994).

${ }^{2}$ H. Ikushima and S. Hayakawa, "Electrical Properties of Ag-Doped Barium Titanate Ceramics," Jpn. J. Appl. Phys., 4 [5] 328-36 (1965).

${ }^{3}$ C. Y. Chen and W. H. Tuan, "Effect of Silver on the Sintering and Grain Growth Behavior of Barium Titanate," J. Am. Ceram. Soc., 83 [12] 2988-92 (2000).

${ }^{4}$ J. Zhou, L. Li, Z. Gui, X. Zhang, and D. J. Barber, "Sol-Gel Derived $\mathrm{BaTiO}_{3}$ Thick Films with Embedded Silver Nanoparticles: Preparation and Dielectric Properties," Nanostruct. Mater., 8 [3] 321-28 (1997).

${ }^{5}$ R. Zuo, L. Li, and Z. Gui, "Cofiring Behaviors between $\mathrm{BaTiO}_{3}$-Modified Silver-Palladium Electrode and Pb-Based Relaxor Ferroelectric Ceramics," Mater Chem. Phys., 70 [2] 326-29 (2001).

${ }^{6}$ N. Halder, A. D. Sharma, S. K. Khan, A. Sen, and H. S. Maiti, "Effect of Silver Addition on the Dielectric Properties of Barium Titanate Based Low Temperature Processed Capacitors," Mater. Res. Bull., 34[4] 545-50 (1999).

${ }^{7}$ H. C. Ling, "Diffusion of Sputtered V, Ni, and Ag in Lead Magnesium Niobate Ceramic," J. Am. Ceram. Soc., 72[2] 770 (1989).

${ }^{8}$ G. H. Maher, "Effect of Silver Doping on the Physical and Electrical Properties of PLZT Ceramics," J. Am. Ceram. Soc., 66 [6] 408-13 (1983).

${ }^{9}$ A. C. Caballero, E. N. P. Duran, C. Moure, M. Kosec, Z. Samardzija, and G. Drazic, "Ceramic-Electrode Interaction in PZT and PMN-PZT Multilayer Piezoelectric Ceramics with Ag/Pd 70/30 Inner Electrode," J. Mater. Sci., 32 [10] 3257-62 (1997).

${ }^{10}$ H. Kanai, O. Furukawa, S. Nakamura, M. Hayashi, M. Yoshiki, and Y. Yamashita, "Effect of Silver Doping on the Reliability of $\left(\mathrm{Pb}_{0.875} \mathrm{Ba}_{0.125}\right)\left[\left(\mathrm{Mg}_{1 / 3^{-}}\right.\right.$
$\left.\left.\mathrm{Nb}_{2 / 3}\right)_{0.5}\left(\mathrm{Zn}_{1 / 3} \mathrm{Nb}_{2 / 3}\right)_{0.3} \mathrm{Ti}_{0.2}\right] \mathrm{O}_{3}$ Relaxor Dielectric Ceramics," J. Am. Ceram. Soc., 78 [5] 1173-78 (1995).

${ }^{11}$ H. Kanai, O. Furukawa, S. Nakamura, and Y. Yamashita, "Role of $\mathrm{PbO}$ and $\mathrm{Ag}$ on Insulation Resistance Degradation in Relaxor-Based MLCs," J. Am. Ceram. Soc., 78 [6] 1657-60 (1995).

${ }^{12}$ H. J. Hwang, T. Nagai, T, Ohji, M. Sando, M. Toriyama, and K. Niihara, "Curie Temperature Anomaly in Lead Zirconate Titanate/Silver Composites," J. Am. Ceram Soc., 81[3] 709-12 (1998).

${ }^{13}$ Y. Sato, H. Kanai, and Y. Yamashita, "Effects of Silver and Palladium Doping on the Dielectric Properties of $0.9 \mathrm{~Pb}\left(\mathrm{Mg}_{1 / 3} \mathrm{Nb}_{2 / 3}\right) \mathrm{O}_{3}-0.1 \mathrm{PbTiO}_{3}$ Ceramics," J. Am. Ceram. Soc., 79 [1] 261-65 (1996).

${ }^{14}$ D. J. Lewis, D. Gupta, M. R. Notis, and Y. Imanaka, "Diffusion of ${ }^{110 m} \mathrm{Ag}$ in Polycrystalline and Single-Crystal Lead-Containing Piezoelectric Ceramics," J. Am. Ceram. Soc., 84 [8] 1777-84 (2001).

${ }^{15}$ R. Zuo, L. Li, R. Chen, and Z. Gui, "Sintering Characteristics and Dielectric Properties of Silver-Doped PMN-PZN-PT Relaxor Ferroelectric Ceramics," $J$. Mater. Sci., 35 [11] 5433-36 (2000).

${ }^{16} \mathrm{C}$. Y. Chen and W. H. Tuan, "Evaporation of Ag during Co-firing with $\mathrm{BaTiO}_{3}$," J. Am. Ceram. Soc., 83 [7] 1693-98 (2000).

${ }^{17}$ H. C. Ling and A. M. Jackson, "Correlation of Silver Migration with Temperature-Humidity-Bias (THB) Failure in Multilayer Ceramic Capacitors," IEEE Trans. Compon., Hybrids, Manuf. Technol., 12 [1] 130-37 (1989).

${ }^{18}$ J. C. Lin and J. Y. Chan, "On the Resistance of Silver Migration in Ag-Pd Conductive Thick Films under Humid Environment and Applied d.c. Field," Mater. Chem. Phys., 43 [2] 256-65 (1996).

${ }^{19}$ V. Bheemineni, E. K. Chang, M. Lal, M. P. Harmer, and D. M. Smyth, "Suppression of Acceptor Solubilities in $\mathrm{BaTiO}_{3}$ Densified in Highly Reducing Atmosphere," J. Am. Ceram. Soc., 77 [12] 3173-76 (1994).

${ }^{20} \mathrm{~K}$. H. Westmacott, C. W. Fountain, and R. J. Stirton, "On the Spacing of Dispersed Obstacles," Acta Metall., 14, 1628-29 (1966).

${ }^{21}$ U. F. Kocks, "On the Spacing of Dispersed Obstacles," Acta Metall., 14, 1629-31 (1966).

${ }^{22}$ R. D. Shannon, "Revised Effective Ionic Radii and Systematic Studies of Interatomic Distances in Halids and Chalcogenides," Acta Crystallogr., Sect. A: Found. Crystallogr., 32, 751-67 (1976).

${ }^{23}$ N.-H. Chan, R. K. Sharma, and D. M. Smyth, "Nonstoichiometry in Undoped $\mathrm{BaTiO}_{3}$," J. Am. Ceram. Soc., 64 [9] 556-59 (1981).

${ }^{24}$ N.-H. Chan, R. K. Sharma, and D. M. Smyth, "Nonstoichiometry in AcceptorDoped $\mathrm{BaTiO}_{3}$," J. Am. Ceram. Soc., 65 [3] 167-69 (1982).

${ }^{25}$ N.-H. Chan and D. M. Smyth, "Defect Chemistry in Donor-Doped $\mathrm{BaTiO}_{3}$," J. Am. Ceram. Soc., 67 [4] 285-89 (1981). 